\title{
Arte na urgência: o caso do MASP 2015-20191
}

\author{
Lilia Schwarcz
}

\begin{abstract}
Resumo
O objetivo desse artigo é explorar o tradicional debate entre arte e política, a partir do caso do Masp e em especial de uma exposição: Histórias da sexualidade (2017). O texto inicia fazendo um histórico do Masp para depois explorar as contradições do contexto e da exposição em questão.
\end{abstract}

\begin{abstract}
The aim of this article is to explore the traditional debate about art and politics, having a specific object: the Masp and mainly one exhibition called Sexuality histories (2017). The article begins with a retrospective of Masp history and analyzes the social context and its contradictions, focusing that exhibition.
\end{abstract}

\footnotetext{
${ }^{1}$ Escrever um texto que implica pensar a própria trajetória nunca é tarefa fácil. Sou curadora adjunta para histórias, do processo que procuro aqui descrever. Por isso faço essa primeira nota como uma espécie de alerta. Por mais que o artigo dialogue com o contexto, com outros processos e protagonistas, ele é, também, uma reflexão de e sobre si.
} 


\section{Antecedentes $^{2}$}

Foi em 1969 que o Museu de Arte de São Paulo, o MASP, abriu ao público seu novo edifício, localizado na histórica e simbólica Avenida Paulista ${ }^{3}$. O prédio e sua arquitetura modernista, feitos das formas do concreto e dos materiais industriais e propositadamente rústicos, contrastavam com os casarões do café que dominaram aquela paisagem desde meados do século XIX. Demonstração da força da burguesia paulistana, o novo projeto tinha tudo para virar ícone da realidade do Estado; o que de fato ocorreu. Ele procurava também representar o arrojo e a excepcionalidade que o Estado de São Paulo queria designar como "seus", mesmo num contexto tão marcado pelo retrocesso político e pela ditadura militar.

À frente do projeto estava um casal de imigrantes vindos da Itália: Pietro Maria Bardi, um profissional com firmes interesses na arte figurativa europeia, e Lina Bo Bardi, arquiteta modernista, responsável pelo projeto do novo Museu. É possível dizer que, de alguma maneira, o casal trazia consigo perspectivas curatoriais e artísticas que fariam parte da própria filosofia mestra da Instituição. A linguagem contemporânea misturada com a mais acadêmica; o "clássico" em diálogo com o, assim chamado, popular; a arte em conversa com o ativismo, a Europa em interlocução com um Brasil que se queria novo, industrial, empreendedor; diferente, mas coadunado com o modernismo europeu. ${ }^{4}$ Tudo num momento de fechamento político e de cerceamento dos direitos dos brasileiros que se opunham ao regime militar.

Coerente com tal vocação expressa por seus dois grandes idealizadores, o novo Masp apresentou seu acervo no $2^{\circ}$ andar, a partir de um suporte em acordo com a arquitetura do Museu e com sua autora - Lina Bo Bardi -, mais conhecido como Cavaletes de Cristal. O concreto áspero, rude, opaco e pesado, contracenava com o cristal, frágil, delicado, transparente e leve, e permitia assim expor a excepcional coleção - valorizando, nesse contexto, as obras europeias do acervo, e as pinturas acadêmicas brasileiras.

Permitia mais: que o público lograsse obter uma visão mais "democrática" dos trabalhos, uma vez que era possível circular mais livremente por entre os trabalhos, criar

\footnotetext{
${ }^{2}$ A primeira parte desse artigo baseia-se, num documento que redigi sobre o MASP, com o auxílio de Adriano Pedrosa e Heitor Martins, para uma publicação do Banco Safra, em 2017. Já a segunda parte é pautada na minha própria experiência como curadora adjunta para histórias do MASP e em especial acerca da exposição "Histórias da sexualidade".

${ }^{3}$ O museu foi primeiramente instalado na rua 7 de Abril, na região central de São Paulo. Apenas em 1986, com projeto de Lina Bo Bardi e curadoria de Pietro Maria Bardi ele se transfere para a Avenida Paulista.

${ }^{4}$ Por fugir do escopo desse artigo apresento aqui dois livros sobre Lina e Pietro Maria Bardi. (Aguilar, Nelson. (2019) Pietro Maria Bardi: construtor de um Novo Paradigma cultural. Campinas, Ed. Unicamp. Lima, Zeuler. (2021) Lina Bo Bardi: O que eu queria era ter história. São Paulo, Companhia das Letras.)
} 
seus próprios percursos e, ademais, observar não só o lado externo, como aquele interno das telas, ficando exposta as estruturas, os registros dos locais onde a obra transitara e até mesmo os valores pagos pelos trabalhos no passado, ficando aparentes os recibos de compra, venda, anúncios e promoções.

O modelo expositivo não era, portanto, mero detalhe; na verdade, ele sinalizava para um dos objetivos centrais da curadoria: a dessacralização das obras de arte, e a experiência de apresentar trabalhos acadêmicos e clássicos de forma renovada. Por fim, o material expositivo provocava o público para adentrar e enfrentar o ambiente protegido dos objetos de arte. ${ }^{5}$

A mostra permanente encontrava-se em diálogo com mais outra, aberta paralelamente no $1^{\circ}$. andar da Instituição. Era por lá que a exposição $A$ mão do povo brasileiro expunha mais de mil objetos, que incluíam carrancas, ex-votos, santos, tecidos, vestuário, mobiliário, ferramentas, utensílios de cozinha, instrumentos musicais, adornos, esculturas, figuras religiosas, brinquedos, bem como pinturas e esculturas; todos reunidos sob a designação de "trabalhos". Era a experiência de Lina que dialogava com a "noção de povo" brasileiro e fazia com que ele entrasse no interior do museu, numa proposta de acordo com o momento que o país vivia.

A pretensa distância entre os andares e suas exposições visava novamente provocar, evitando classificações impregnadas de hierarquias internas a esse mundo - entre arte e artefato; erudito e popular, universal e nacional ou regional - e convidar o público a circular entre os andares, estabelecendo uma conversa, por certo tensa, entre as duas mostras. 6

Outra exposição foi aberta no contexto de inauguração do MASP, na avenida Paulista. Ela se chamava Playgrounds e dispunha, no vão livre do Museu, uma série de esculturas com as quais o público era convidado a interagir. O artista Nelson Leirner, devolvia com sua obra a vocação pública de uma instituição localizada num dos pontos mais agitados da capital paulista. Era como se a cidade habitasse o Museu e incluísse o MASP na sua vida e circulação. ${ }^{7}$

Tratava-se, pois, de uma tríade - quase um triângulo simbólico - que colocava em contato uma pinacoteca de pinturas do cânone europeu, mas devidamente enervadas por

\footnotetext{
5 Pedrosa, Adriano e Proença, Luiza (org.). (2015) Concreto e cristal: o acervo do MASP nos cavaletes de Lina Bo Bardi. São Paulo, MASP/ Cobogó.

${ }^{6}$ Em 2016 a exposição seria remontada já sob a direção de Adriano Pedrosa e a curadoria dele e de Tomás Toledo. (Pedrosa, Adriano et al. (2016) A Mão do Povo Brasileiro. São Paulo, MASP.

${ }^{7}$ Pedrosa, Adriano; González, Julieta e Proença, Luiza. (2016) Playgrounds 2016. São Paulo, MASP
} 
um projeto expositivo que causava ruído à contemplação passiva; um playground no espaço aberto, e a arte dita popular no piso intermediário.

A intenção, nos termos de Lina Bo Bardi, era tirar do museu "o ar de igreja”, 8 evitar o caráter imponente e não convidativo do edifício, e trazer a arte para perto do público e da visitação. Era assim que o novo Masp agora localizado na Avenida Paulista abria suas portas. ${ }^{9}$

\section{Histórias}

Foi tendo em vista esse legado que um novo projeto curatorial foi implementado em 2015, sob a liderança de Adriano Pedrosa. ${ }^{10}$ Foi também nesse contexto que fui contratada como curadora adjunta para histórias, do MASP. O plano apresentado tinha como viga mestra a noção de história. Tanto a história como disciplina, como a história enquanto narrativa: discursos que costumamos contar. História pensada como disciplina do passado, mas também estória, aquela que inclui o mito e a ficção. Outro eixo importante era lidar com a memória da própria instituição, recuperando e relendo tanto exposições anteriores, como o acervo e os documentos armazenados por antigas administrações.

História e memória são perspectivas de entendimento do passado que nem sempre se confundem ou se complementam. ${ }^{11} \mathrm{Na}$ verdade, entre elas se estabelece um território de embate; um território vivo. Nem sempre a história consegue acreditar na memória. Já a memória desconfia de qualquer procedimento de reconstituição do passado que não traga no seu centro do debate os direitos da lembrança - direitos de vida, de rememoração da experiência e de subjetividade.

É pensando na ideia de que a memória não significa uma volta fetichizada ou estanque ao passado, que o novo grupo curatorial do Masp selecionou a noção de que história é como o "presente do passado", mas também o passado que está sempre atravessado por questões do presente. Afinal, ninguém retorna ao passado sem estar munido dos temas de sua geração.

Nesse sentido, a filosofia do grupo que assumiu o Masp em $2015^{12}$ procurou revisitar sua produção, acervo, ideias, arquiteturas e expografias. Mais ainda, buscou "traduzir" essa

\footnotetext{
${ }^{8}$ Bardi, Lina Bo. (1970) “Explicações sobre o Museu de Arte”. O Estado de São Paulo, 05 de abril.

${ }^{9}$ Me refiro a "novo Masp" pois o Museu foi, de fato criado em 1947, na rua 7 de abril.

${ }^{10}$ (Rio de Janeiro, 1965 - ). Curador, colecionador e artista brasileiro, é diretor artístico do MASP desde 2014.

${ }^{11}$ Nora, Pierre. (1993) “Memória e História. A problemática dos lugares". Proj. História, São Paulo, v.10, dezembro.

12 O grupo que assumiu em 2015, junto com a presidência de Heitor Martins, era composto por: Adriano
} - 199 - 
sua origem, não se limitando aos termos que impactaram o contexto dos anos 1960. O momento era outro, com um Brasil ainda mais múltiplo, uma Avenida Paulista particularmente movimentada, atuando como centro e palco para todo tipo de manifestação. Mas o momento também anunciava revés político e a face mais dura da ditadura militar. Por isso, o casal sempre imprimiu ao Masp um lugar de resistência e contestação a partir das artes visuais.

E foi com esse espírito que o novo grupo curador retomou os trabalhos do Museu. Não de maneira nostálgica e muito menos elevatória. Ao contrário, o objetivo foi revisitar, criticamente, os momentos inaugurais do Masp, apostando na certeza de que não se separam marcadores de tempo como presente e passado. Nesse sentido, qualquer retomada é antes um recomeço, pois indica propósitos, vislumbra limitações, reconhece potencialidades.

O braço forte do novo projeto centrava-se na ideia das "nossas histórias". Partindo de temas amplos, a ideia era revisitar e embaralhar o acervo do Museu, misturando obras do acervo do MASP com outras vindas de coleções nacionais e estrangeiras. A meta é friccionar temporalidades, suportes, regiões, gêneros, tudo num contexto democrático que marcou a Terceira República Brasileira.

Mas o contexto mudou, desde 2015, com o processo impeachment da presidente Dilma em 2016 e a formação de uma imensa onda retrógrada que desaguaria no Brasil. Com isso, temas que pareciam mais "inócuos", digamos assim, como sexualidade, histórias afrobrasileiras, histórias das mulheres ganharam uma nova camada de significados. O que parecia dado precisa ser mais uma vez conquistado.

\section{Casa nova, tempo novo}

Foi a partir das perspectivas acima expressas que a nova curadoria definiu suas principais metas e exposições. Reabriu no $2^{\circ}$. andar os Cavaletes de Cristal, a partir de novas estruturas expositivas que procuraram otimizar o modelo de 1968, e de uma seleção dos trabalhos do acervo, desde então dispostos cronologicamente (do mais recente ao mais antigo), sem divisões entre nacional e estrangeiro, consagrado e fora do cânone, arte e artesanato. A mostra também questiona um certo princípio de eternização de Pinacotecas,

Pedrosa (Diretor Artístico), Lilia Schwarcz (Curadora-adjunta de Histórias), Julia Bryan-Wilson (Curadoraadjunta de Arte Moderna e Contemporânea), Marcia Arcuri (Curadora-adjunta de Arte Pré-Colombiana), Maria Inês Rodríguez (Curadora-adjunta de Arte Moderna e Contemporânea), Sandra Benites (Curadoraadjunta de Arte Brasileira), Tomás Toledo (Curador-chefe), Fernando Oliva (Curador), Isabella Rjeille (Curadora), Amanda Carneiro (Curadora-assistente) e Matheus Andrade (Assistente de pesquisa). 
que costumam expor e manter expostas as obras consideradas "representativas", que, não por coincidência, são em geral, de origem europeia, no máximo norte-americana. A ideia também não é cristalizar as obras lá expostas, mas ir incluindo outros trabalhos do acervo do MASP, obras emprestadas de outras instituições sob o regime de comodato e novas aquisições, sobretudo aquelas advindas de outras exposições abertas no Museu. Por isso, a mostra ganhou o título, "Um acervo em formação", justamente para desestabilizar a ordem classificatória ainda vigente nas "histórias da arte" mais canônicas e também por visar a transformação.

Recebida com algumas críticas, que acusavam a nova curadoria de ser por demais "nostálgica", 13 a exposição foi logo acolhida pelo público, que dobrou a visitação e fez fila em dia de Natal de 2015.

Inaugurou-se no 1o. andar a exposição A mão do povo brasileiro; na verdade uma mostra revista e adaptada ao novo contexto. ${ }^{14}$ Nesse caso, a coincidência entre trabalhos apresentados no evento de 1969 e outros introduzidos expressamente para a mostra de 2016 revelava um jogo de dissonâncias e reflexos entre as duas exposições. A ideia foi repensar o assim chamado "popular", por meio de outros tempos, escolas e produções. Uma mostra plasticamente próxima da anterior, mas que, observada por meio de seus detalhes, interpelava o público a reconhecer como o passado sempre se apresenta com novas vestimentas na lógica do presente.

Para "traduzir" e "reler" a história interna do Masp, também foi aberta a exposição Playgrounds (2016), com novos objetos idealizados por Nelson Leirner, a essas alturas, não mais um jovem artista em início de carreira, mas um representante reconhecido das artes plásticas nacionais. A exposição buscava dialogar, igualmente, com outros programas e exposições do Museu. Playgrounds entrava no concerto da primeira mostra de "histórias", com Histórias da infância ficando aberta de abril a julho de 2016. Logo no convite apareciam duas obras teoricamente distantes, no tempo e no espaço. Lá estavam As meninas Cahen d'Anvers (1881), de Pierre-Auguste Renoir, ladeadas pela fotografia de Bárbara Wagner, de 1980 - parte da série Brasília teimosa.

\footnotetext{
13 Vide, por exemplo, texto publicado na Revista Piauí (Scarpin, Paula. (2015) “As telas suspensas de Lina Bo Bardi. O MASP reabilita os cavaletes de cristal". Revista Piauí, edição 111, dezembro.

${ }^{14}$ A curadoria era de Adriano Pedrosa e Tomas Toledo.
} 


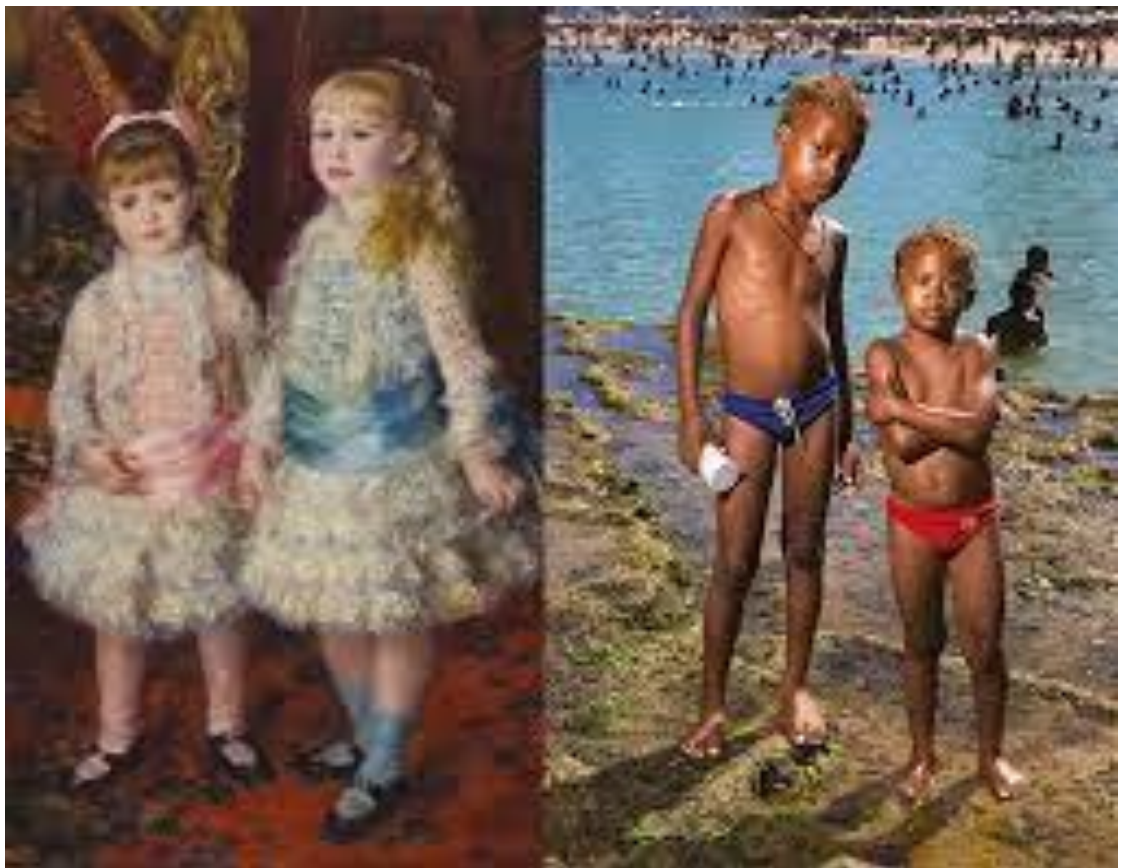

Figura 1- Imagem para o convite da exposição ‘Histórias da infância' (MASP/2016)

Ficava clara, também, a intenção da curadoria, que pretendia colocar em tensão tempos e suportes: de um lado um dos cartões postais do Museu e de outro uma fotografia mais recente; de um lado duas meninas europeias e de outro dois meninos de Recife; nos dois casos porém destaca-se o orgulho dos e das modelos. A partir delas, o MASP convidava um público mais jovem a experimentar os espaços do Museu, bem como mostrava a intenção de não querer estabilizar conhecimentos prévios da, assim chamada, história da arte universal. ${ }^{15}$

Essa foi a primeira mostra das "histórias"; exposições que misturam cronologias, suportes, geografias, espaços e temporalidades a partir de temas abrangentes. Elas procuram assim questionar e rever narrativas assentadas, que supõe uma certa evolução única das escolas, movimentos e estilos artísticos, sem deixar claro o índice que as articula: a cultura ocidental. É sempre um seleto grupo, em geral masculino, que é apresentado nessas exposições, criando-se uma postura reverencial diante dessa história da arte no singular. Conforme explicou o historiador da arte Steve Edwards: "o cânone é uma condição estrutural da história da arte"16 e pode-se dizer que esse é um dos ramos onde o imperialismo e a colonização se inscreveram de maneira mais enraizada, sendo o Museu

\footnotetext{
${ }^{15}$ A mostra era curada por Luciano Migliaccio, Fernando Oliva e Lilia Schwarcz. Ela também estreitou relações entre instituições, tendo seguido, um pouco reconfigurada, para o Sesc Interlagos.

${ }^{16}$ Edwards, Steve. (1999) "Introduction". In: Art and its Histories. New Haven, Connecticut, Yale University, p.13.
} 
seu aparato mais estrutural. É a partir dele que se desenvolve todo um arsenal expresso em livros, textos, biografias e monografias, ensaios e artigos ilustrados que colocam em circulação modelos criados por escolas do ocidente, prontamente multiplicados nas colônias e ex-colônias. São formas de ver que supõe mérito e talento onde muitas vezes subsiste a convenção; universalidade onde reside a norma.

Como era a primeira, Histórias da infância foi aberta com obras basicamente do acervo; todas propositadamente colocadas alguns centímetros mais baixas do que estabelece a regra, isso para que as crianças pudessem apreciar as pinturas numa altura compatível com seus tamanhos.

A programação se articulava (e continua se articulando), fundamentalmente, por meio dessas tantas histórias. Nesse projeto obras de autoria de brasileiros são dispostas ao lado de estrangeiros, trabalhos da antiguidade contracenam com o contemporâneo, acabando por borrar fronteiras e fazendo do interno, externo e vice-versa. Por isso, essas são histórias fragmentadas pois marcadas não só por diferenças sociais expressas por diferentes origens, classes, gêneros, sexualidades, regiões e gerações, mas também pois buscam ressonâncias para além dos limites nacionais.

Mas a primeira exposição não deixava claro o barulho que viria a partir da segunda mostra: Histórias da sexualidade.

\section{Sob o clima do ódio}

O ano de 2017 se abriu, todavia, tenso em muitos e vários aspectos. O processo de impeachment de Dilma por mais que tenha seguido o ritual judiciário e legal, abriu a tampa da democracia no Brasil e escancarou o autoritarismo ${ }^{17}$.

Entre o início do seu segundo mandato, em janeiro de 2015, e a votação do impeachment da presidente da República, em agosto de 2016, cresceu o grupo dos que se sentiram no direito de impor um veto à escolha democrática da sociedade: uma questão era contestar a má administração do governo, que ampliava a dívida do Estado; outra era propor uma mudança institucional, com manobras jurídicas duvidosas, e com o objetivo claro de tirar do poder a presidente.

Esse grupo reunia um conjunto muito variado de interesses politicamente hostis ao governo federal - empresários, industriais, banqueiros, parlamentares, jornalistas, juízes, setores das classes médias urbanas -, bastante favoráveis a adaptar a lei a seus interesses

\footnotetext{
17 Sobre o tema escrevi Sobre o autoritarismo brasileiro. (2018) São Paulo, Companhia das Letras.
} 
políticos imediatos. ${ }^{18}$ Saiu daí uma espécie de coalizão oposicionista que operava de maneira autônoma, mas com coincidência de objetivos. Além do mais, encontraram um denominador comum - a derrubada do governo. Essa coalizão mobilizou as ruas e agregou um punhado de lideranças parlamentares dispostas a atuar como executores de ações contrárias aos interesses do governo dentro e fora do Congresso Nacional.

Em um ano e meio, desabou sobre o governo de Dilma Rousseff uma sucessão inacreditável de crises: o aumento do desemprego e a recessão econômica; as denúncias de corrupção chegavam a toda hora de Curitiba, com intenso foco no PT e, sobretudo, em Lula; os protestos e a intolerância cresciam rápido nas ruas; o Congresso Nacional boicotava iniciativas do governo, na mesma proporção em que o vice-presidente da República, Michel Temer, conspirava pela queda da titular. Para piorar, o rompimento da barragem de Fundão, em Mariana, no Estado de Minas Gerais, provocou o maior desastre ambiental já conhecido no país, com vítimas fatais. Junto com ele, chegaram os surtos de zika vírus e de dengue, que ajudaram a revelar a falta de controle do governo, além de uma política pouco definida nessas áreas. ${ }^{19}$ Nem a derrota do Brasil contra a Alemanha, por 7 a 1, na Copa do Mundo de 2014, abalou tanto os nervos dos brasileiros. Se até lá o apagão parecia se concentrar no campo de futebol, agora ele invadia o dia a dia dos brasileiros.

Montou-se, então, um verdadeiro roteiro político com a explicação de que a crise estava vinculada ao governo e à personalidade de Dilma Rousseff. Mas existiu uma novidade política na consecução desse roteiro - ele manteve intocado o ritual democrático. Fazer uso de procedimentos rotineiros da democracia e obedecer formalmente à letra das leis vigentes no país em favor de objetivos contrários aos valores democráticos preservados pelas instituições era manobra política inédita na história brasileira.

Serviu de base do processo o recurso às chamadas "pedaladas fiscais". O termo é usado pelos técnicos da área econômica para indicar a postergação pela União de um pagamento de um mês para o outro ou de um ano para o outro. O expediente das pedaladas engorda o caixa do Tesouro e permite inflar artificialmente o superávit primário, de modo a criar a ficção de que o resultado obtido pelo governo melhorou - e esse fora um

\footnotetext{
${ }^{18}$ Para agentes políticos de oposição: Santos, Wanderley Guilherme dos. (2017) A Democracia impedida; o Brasil no século XXI. Rio de Janeiro, FGV Editora; Reis, Fábio Wanderley. “Crise política: a 'opinião pública' contra o eleitorado". In Miguel, Luis Felipe e Biroli, Flávia. (org.). (2017) Encruzilhadas da democracia. Porto Alegre, Editora ZOUK.

${ }^{19}$ Para crises do segundo governo de Dilma Rousseff, ver: Almeida, Rodrigo de. (2016) À sombra do poder; os bastidores da crise que derrubou Dilma Rousseff. São Paulo, Leya.
} 
procedimento já utilizado por gestões anteriores do governo federal. Já a metáfora é literal - afinal, se um ciclista parar de pedalar, a bicicleta tomba. ${ }^{20}$

O pedido de impeachment foi acolhido pelo então presidente da Câmara dos Deputados, Eduardo Cunha, do PMDB, em dezembro de 2015. ${ }^{21}$ A partir daí passou-se a obedecer formalmente à letra das leis vigentes no país, mas usá-los em favor de objetivos contrários aos valores democráticos preservados pelas instituições. Tudo foi feito sem o devido juízo crítico e sem a avaliação do custo dessa operação para a própria democracia brasileira. ${ }^{22}$

Um sinal eloquente da temperatura elevada do país pode ser encontrado na decisão da Secretaria de Segurança Pública do Distrito Federal ao erguer uma cerca metálica de dois metros de altura, em toda a extensão da Esplanada dos Ministérios, bem no dia da votação do impeachment de Dilma. O objetivo era claro, quase didático: separar a população que quisesse se manifestar a favor ou contra. $\mathrm{O}$ muro representava de maneira real, e não mais simbolicamente, a divisão do país, agora instalada na capital do Brasil.

O impeachment da presidente escancarou a profundidade da crise que se instalava no país. E o processo se agudizou com uma descrença bastante generalizada diante da política e dos políticos. Uma descrença também nas, assim chamadas, minorias sociais: mulheres, negros, quilombolas e as pessoas LGTQI+

\section{O caso da exposição Histórias da sexualidade no MASP}

O ano de 2017 abriu-se sob o clima da intolerância, o qual acertou em cheio o mundo das artes. A exposição Queermuseu - Cartografias da Diferença na Arte Brasileira, estava em cartaz há quase um mês no Santander Cultural, em Porto Alegre. Foi cancelada, entretanto, no dia 10 de setembro de 2017 após uma grande onda de protestos e de manifestações nas redes sociais. Segundo a maior parte daqueles que agora se levantavam contra a

${ }^{20}$ Para "pedaladas fiscais" e o processo de impeachment, ver: Almeida, Rodrigo de. À sombra do poder; os bastidores da crise que derrubou Dilma Rousseff. Op. cit.; Safatle, Cláudia, Borges, João, Oliveira, Ribamar. (2016) Anatomia de um desastre; os bastidores da crise econômica que mergulhou o país na pior recessão de sua história. São Paulo, Portfolio-Penguin.

${ }^{21}$ Para Eduardo Cunha, ver: Almeida, Rodrigo de. À sombra do poder; os bastidores da crise que derrubou Dilma Rousseff. Op. cit; Avritzer, Leonardo. "Democracia no Brasil: do ciclo virtuoso à crise política aberta". In: Botelho, André e Starling, Heloisa Murgel (org.). (2017) República e Democracia; impasses no Brasil contemporâneo. Minas Gerais, Editora UFMG.

22 Para utilização do ritual democrático e sua originalidade no Brasil, ver: Santos, Wanderley Guilherme dos. A Democracia impedida; o Brasil no século XXI. Op. cit.; Santos, Fabiano; Szwako, José. "Impasses políticos e institucionais no cenário atual". In Botelho, André e Starling, Heloisa Murgel (org.) República e Democracia; impasses no Brasil contemporâneo. Op. cit. 
continuidade da mostra, as obras promoviam blasfêmia contra símbolos religiosos e também apologia à zoofilia e pedofilia.

A exposição, que contava com a curadoria de Gaudêncio Fidelis ${ }^{23}$, reunia 270 trabalhos de 85 artistas que abordavam a temática LGBT, incluindo questões que iam de gênero à diversidade sexual. As obras - que buscavam percorrer o período histórico de meados do século XX até os dias de hoje - eram assinadas por artistas reconhecidos como Adriana Varejão, Cândido Portinari, Fernando Baril, Hudinilson Jr., Lygia Clark, Leonilson e Yuri Firmesa.

Nas redes, as mensagens e vídeos mais compartilhados pelos críticos e movimentos religiosos referiam-se à pintura de um Jesus Cristo com vários braços (a obra Cruzando Jesus Cristo Deusa Schiva, de Fernando Baril ${ }^{24}$ ) e a outra tela Criança viada travesti da lambada e Criança viada deusa das águas, da artista Bia Leite. ${ }^{25}$

Num tipo de movimento hoje bastante conhecido, mas na época nem tanto, foi ficando claro que as inúmeras mensagens e vídeos que circulavam nas redes eram lideradas principalmente pelo Movimento Brasil Livre (MBL), que ganhara espaço na mídia, ao promover manifestações contra Dilma Rousseff quando ainda era presidente. Eles exigiam o encerramento da exposição, em um caso jamais visto desde o início da Terceira República brasileira, quando a censura da ditadura foi abolida e se transformou em artigo da Constituição de 1988. Dessa feita, ecoando um discurso de muito ódio, nessas que eram reações orquestradas, o grupo pregava ainda um boicote ao banco Santander.

Surfando na onda da extrema direita retrógrada, o prefeito de Porto Alegre, Nelson Marchezan Jr. (PSDB) ${ }^{26}$ aproveitou para ganhar pontos eleitoralmente e se manifestou contra "imagens de zoofilia e pedofilia". Já o banco Santander num primeiro momento esclareceu, por meio de nota, que trabalhos da mostra poderiam provocar "um sentimento contrário" daquilo que efetivamente apresentavam. Elas teriam sido criadas "justamente para nos fazer refletir sobre os desafios que devemos enfrentar em relação a questões de gênero, diversidade, violência entre outros". Dois dias depois, todavia, o banco voltou

23 (Gravataí/RS, 1965-). Curador e historiador de arte especializado em arte brasileira moderna e contemporânea e arte da América Latina. É Mestre em Arte pela New York University (NYU) e Doutor em História da Arte pela Universidade do Estado de Nova Iorque (SUNY).

24 (Porto Alegre/RS, 1948-). Pintor, professor e desenhista.

25 (Fortaleza/CE, 1990-). Artista plástica, concentra os estudos em pintura, gravura, desenho e cinema; a colagem é o que guia o processo criativo.

26 (Porto Alegre/RS, 1971-). Advogado e político brasileiro. Foi prefeito de Porto Alegre entre 2017 e 2020. 
vergonhosamente atrás. Acabou por ceder às pressões dos críticos com medo de um forte boicote contra o Santander.

Em nova nota, no dia de fechamento da exposição, o Santander Cultural pediu desculpas aos que haviam se sentido ofendidos e acrescentou. "Ouvimos as manifestações e entendemos que algumas das obras da exposição Queermuseu desrespeitam símbolos, crenças e pessoas, o que não está em linha com a nossa visão de mundo. Quando a arte não é capaz de gerar inclusão e reflexão positiva, perde seu propósito maior, que é elevar a condição humana". Na sequência fechou a mostra que ficaria originalmente em cartaz até o dia 8 de outubro. ${ }^{27}$

Incoerente, a Instituição que tivera tempo de avaliar a exposição e inclusive elaborar nota apoiando a iniciativa, voltava fragorosamente atrás, sendo que os motivos que a fizeram defender a exposição, num comunicado oficial, em poucos dias viravam razão de recusa.

A decisão não passou porém desapercebida. Gerou outra grande polêmica no meio artístico e entre internautas, que acusaram o banco de praticar a censura. O curso dos acontecimentos foi tão ligeiro que o próprio curador da exposição disse ao O Globo ter sido pego de surpresa com a notícia. "Já fiz duas bienais do Mercosul, nunca tinha visto algo parecido. As manifestações foram muito organizadas e se debruçaram sobre algumas obras muito específicas, que não dão a verdadeira dimensão da exposição.

A artista Adriana Varejão, que participava da exposição com a obra Cena de interior (1994), e era acusada de pedofilia, reagiu explicando que o trabalho em questão era adulto e feito para adultos. "A pintura é uma compilação de práticas sexuais existentes, algumas históricas (como as Chungas, clássicas imagens eróticas da arte popular japonesa) e outras baseadas em narrativas literárias ou coletadas em viagens pelo Brasil. $O$ trabalho não visa julgar essas práticas". Todo feito em tela, mas parecendo papel de arroz, o trabalho faz parte da série em que a artista vai ao Oriente para reler o barroco no Brasil. Adriana, que tem trabalhos nas coleções do Tate Modern, de Londres, no Museu Guggenheim, em Nova York, e na Fundação La Caixa, em Barcelona, e nos principais museus brasileiros, disse ainda que, como artista, apenas busca jogar luz sobre coisas que muitas vezes existem escondidas.

${ }^{27}$ A exposição foi viabilizada pela captação de 800 mil reais por meio da Lei Rouanet. 


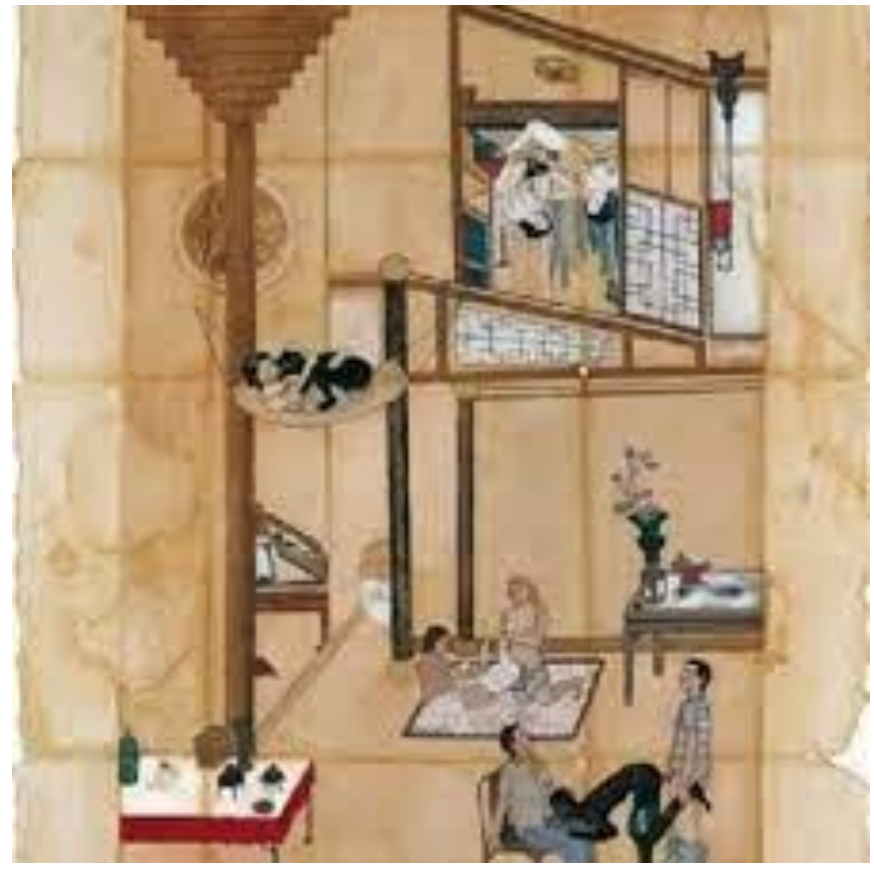

Figura 2 - Adriana Varejão. Cena de Interior. (1994)

A pintura apresenta uma série de jogos sexuais, misturando gêneros, raças, passado e presente, e fazendo alusão a uma arte desenvolvida no oriente por séculos ${ }^{28}$. Além do mais, mistura citações do artista Jean-Baptiste Debret e referência aos Chungas japoneses dos séculos XVIII e XIX em coerência com um processo de trabalho bastante próprio, em que Adriana Varejão introduz citações a outros documentos visuais, que são devidamente alterados. Nada disso fez com que a obra e sua autora deixassem de entrar nas vogas de cancelamento virtual, prática ainda nova no Brasil daquela época.

Também não foi a primeira vez que trabalhos como esses ocasionaram reclamações, projetos de censura e censura. Por exemplo, em 2006, o Banco do Brasil retirou do Centro Cultural Banco do Brasil (CCBB) do Rio de Janeiro a obra Desenhando em Terços, da artista plástica Márcia $X$, que mostrava a foto de dois terços que desenhavam dois pênis e formavam também uma cruz.

Mas nesse ano seria diferente. Nesse caso fatos isolados virariam eventos, com claro significado cultural e político ${ }^{29}$, e seriam recuperados em outras circunstâncias. A performance do artista Wagner Schwartz realizada no dia 26 de setembro do mesmo ano no Museu de Arte Moderna (MAM), localizado no Ibirapuera, na Zona Sul de São Paulo, gerou

\footnotetext{
${ }^{28}$ Escrevi longamente sobre essa obra no livro de minha autoria chamado Pérola imperfeita: a história e as histórias de Adriana Varejão. (2014) Rio de Janeiro, Cobogó.

${ }^{29}$ Faço referência aqui ao texto de Marshal Sahlins, Ilhas de história, que diferencia um "fato", de um "evento", tomando em conta, justamente, a abrangência cultural que recebe.
} 
também muita polêmica nas redes sociais. Um vídeo que viralizou no Facebook mostrava quando uma criança tocava no pé do artista que dançava nu. O MBL e outros movimentos de direita tomaram novamente a dianteira e acusaram a performance de crime. A apresentação ocorreu somente num dia; numa terça-feira à noite, na estreia do 35을 Panorama de arte Brasileira, tradicional exposição bienal que aborda a arte no país e propõe reflexões sobre identidade e cultura brasileiras. Novamente o Museu ferveu. Segundo o MAM, o evento era aberto a visitantes que estivessem no local e que havia sinalização sobre a nudez na sala onde o espetáculo ocorria.

A performance chamada "La Bête" era inspirada em um trabalho de Lygia Clark, Bichos, que é considerada a obra viva da artista, ultrapassando limites da superfície de um quadro. A série de esculturas com dobradiças permite que o espectador se torne figura atuante na obra, e foi construída com formas geométricas para que se parecessem animais. Já em "La Bête", o a Schwartz, que trabalha há 20 anos com coreografia, manipulava uma réplica de plástico de uma das esculturas da série e se apresentava nu e entregue à performance artística, convidando o público a fazer o mesmo junto com ele.

O MBL voltou à carga divulgando um vídeo nas redes sociais em que chamava a apresentação de "repugnante", "inaceitável", "erotização infantil", "afronta", “crime”, e afirmava que a criança "se sentiu constrangida". O grupo acrescentava que o vereador Fernando Holiday (DEM) iria "tomar as providências sobre o caso da criança induzida a ato libidinoso".

Jair Bolsonaro (PSC-RJ), na época deputado federal, chamou os envolvidos de "canalhas" e categorizou a atividade como "pedofilia". O deputado Marco Feliciano (PSCSP) considerou as cenas "revoltantes" e os envolvidos "destruidores da família". Armou-se o circo retrógrado e quem pode surfar na onda não perdeu oportunidade. Esses políticos jamais haviam pensado em arte, e com certeza não estavam protegendo a criança que viuse envolvida numa disputa do mundo dos adultos.

Em nota, o MAM informou que "o trabalho não tem conteúdo erótico e trata-se de uma leitura interpretativa da obra Bicho, de Lygia Clark". "Importante ressaltar que o material apresentado nas plataformas digitais não apresenta este contexto e não informa que a criança que aparece no vídeo estava acompanhada e supervisionada por sua mãe", explicava a nota do Museu.

Enfim, a temperatura andava elevada e os limites entre arte, ativismo e política claramente explicitados. Foi nessa circunstância, em outubro desse mesmo ano, que estava marcada a abertura de Histórias da sexualidade no Masp. Logo na entrada da exposição o 
texto destacava: "não há lugar, tempo ou circunstância que não crie suas histórias da sexualidade". Afirmava sexo e gênero eram categorias de repertórios ambivalentes, e que combinados aos demais termos levam a construções de alteridades, as quais traduzem hierarquias sociais ao mesmo tempo que as repõe, tanto externa como internamente e por parte dos indivíduos que se auto-classificam.

A exposição Histórias da sexualidade fazia parte de uma programação mais ampla que o Museu de Arte de São Paulo (MASP) vinha, como vimos, desenvolvendo. No ano de 2017, o Museu abria sua programação para o tema das sexualidades; "tão antigo como atual e sempre complexo". O calendário incluía uma série de mostras monográficas - dedicadas a Henri de Toulouse-Lautrec, Wanda Pimentel, Teresinha Soares, Miguel Rio Branco, Tracey Moffatt, Pedro Correia de Araújo, Guerrilla Girls e Tunga, entre outros. Tratava-se de uma grande coletiva com mais de 700 obras, que colocava em tensão diferentes períodos, suportes e territórios - arte Pré-Colombiana, Asiática e Africana, trabalhos europeus e latino-americanos, pinturas e escultura, filmes, vídeos e fotografias, assim como documentos e publicações. Faziam parte da mostra trabalhos do acervo do MASP e outros provenientes de coleções e museus brasileiros e internacionais.

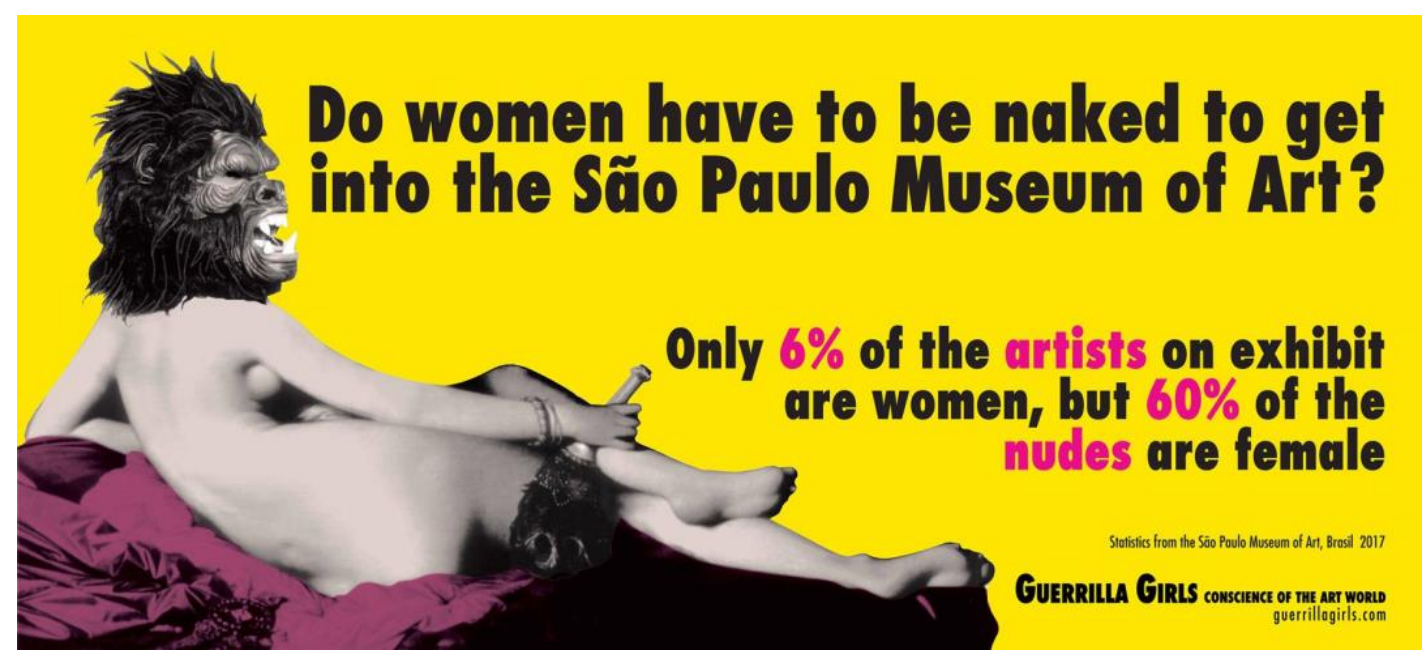

Figura 3 - Guerrilla Girls, 2017. Impressão Digital sobre papel. 32 x 73 cm.

Naquele mesmo ano, o Masp convidara o grupo Guerrila Girls para avaliar o seu acervo. As Guerrilla Girls se definem como um grupo de ativistas feministas que "usam fatos, humor e imagens ultrajantes para expor os preconceitos étnicos e de gênero, bem como a corrupção na política, na arte, no cinema e na cultura pop”. Constituído por ativistas anônimas, e conhecido por usar máscaras de gorila em aparições públicas, o grupo foi formado em 1985 em resposta a uma exposição realizada em 1984 no Museum of Modern 
Art (MoMA), em Nova York chamada International Survey of Recent Painting and Sculpture. Já o Masp abriu exposição com as artistas, 116 trabalhos do grupo, incluindo dois novos cartazes brasileiros que justamente tratavam das exclusões de gênero presentes na história da arte. E o caso do Masp não era diferente, como se pode notar no trabalho acima, com um número grande de artistas masculinos presentes em seu acervo, e com os nus sendo quase que exclusivamente femininos. Um grande happening aconteceu no dia da abertura no final de setembro, e a presença das integrantes do grupo.

Ia ficando claro, porém, que os episódios ocorridos recentemente no Brasil e no mundo tinham o poder de trazer à tona questões relativas à sexualidade e aos limites entre direitos individuais e liberdade de expressão, por meio de embates públicos, protestos e manifestações nas mídias sociais. Estava em curso uma cruzada moral, e a abertura de Histórias da sexualidade não sairia, dessa vez, ilesa.

A exposição vinha sendo concebida desde 2015, e era fruto de intenso trabalho, antecedido por dois seminários internacionais realizados em setembro de 2016 e em maio de 2017. Na semana imediatamente anterior à abertura da mostra já estavam no Brasil e dispostas nas paredes mais de 400 obras reunidas em nove núcleos temáticos e não cronológicos - corpos nus, totemismos, religiosidades, performatividades de gênero, jogos sexuais, mercados sexuais, linguagens e voyeurismos, na galeria do primeiro andar do Museu, e políticas do corpo e ativismos, na galeria do primeiro subsolo. A mostra incluía também uma sala de vídeo no terceiro subsolo, como parte do núcleo voyeurismos.

Algumas obras de artistas do acervo do Masp - como Edgard Degas, Maria Auxiliadora da Silva, Pablo Picasso, Paul Gauguin, Suzanne Valadon e Victor Meirelles eram agora expostas em novos contextos, encontrando outras possibilidades de compreensão e leitura. Ao lado delas, uma seleção de trabalhos de diferentes formatos, períodos e territórios compunham histórias que desafiavam hierarquias e fronteiras entre tipologias e categorias de objetos da história da arte mais convencional. Ali estavam obras da arte pré-colombiana à arte moderna, da chamada arte popular à arte contemporânea, da arte sacra à arte conceitual, incluindo arte africana, asiática, europeia e das Américas, em pinturas, desenhos, esculturas, fotografias, fotocópias, vídeos, documentos, publicações, entre outros.

Nessas histórias, as fronteiras do que é moralmente aceitável deslocavam-se de tempos em tempos, assim como sabemos que os costumes variam entre as culturas e civilizações. Em diversas nações europeias e comunidades indígenas é natural que a nudez seja exposta em lugares públicos; a poligamia é aceita em alguns países islâmicos; há países onde o aborto é livre e outros onde é proibido. Esculturas clássicas que são ícones da história 
da arte não poucas vezes tiveram o sexo encoberto e o mesmo destino tiveram algumas obras tradicionais.

Esse é o caso da famosa obra de Nicolas Poussin, Himeneu travestido assistindo a uma dança em honra de Priapo, concluída entre 1634-38.
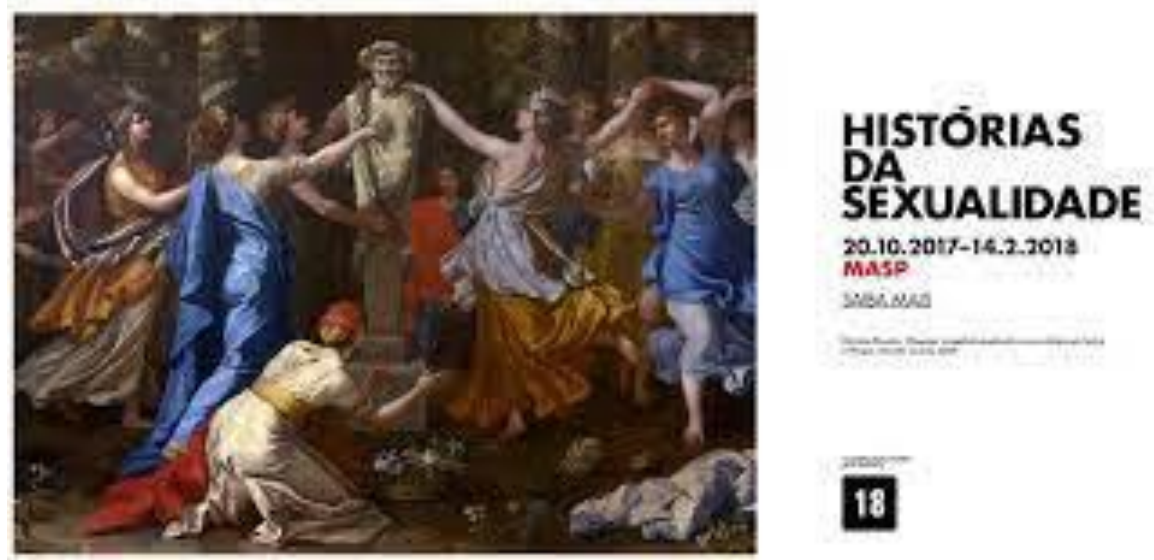

Figura 4 - Cartaz com o aviso da proibição a 18 anos

Na pintura, o artista retrata a história de Himeneu, divindade da boa fortuna dos casais, que, para se aproximar da amada, "transvestiu-se" de mulher em uma festividade em homenagem a Príapo, deus da fertilidade na cultura clássica, representado pela estátua que se encontra no centro da pintura. Em Roma, nas festividades em homenagem a Príapo, eram admitidas somente mulheres, que se vestiam de bacantes, tocavam instrumentos e colocavam flores diante da imagem da divindade. Por isso Himeneu teve que usar de um "disfarce".

O quadro interessava, dessa maneira, tanto por conta da personagem que se transveste, como por causa dos "jogos sexuais" que ele apresenta. Mas um incidente marcou a história desse trabalho. Ao ser restaurado pelo Masp, ficou em evidência o falo ereto de Príapo, que fora devidamente escondido em restauros anteriores.

Mas o ambiente em que a mostra se abriu era bem diverso daquele da equipe que fizera a pesquisa para ela. A pressão no mundo da política chegou logo aos artistas, aos curadores - Adriano Pedrosa, Camila Bechelany, Lilia Schwarcz, e Pablo León de la Barra como à direção do Masp que resolveu incluir um dia antes da abertura a classificação indicativa de 18 anos. Tanto para a exposição como para o catálogo, que ganhou uma significativa e inusitada tarja preta para um livro como esse. 


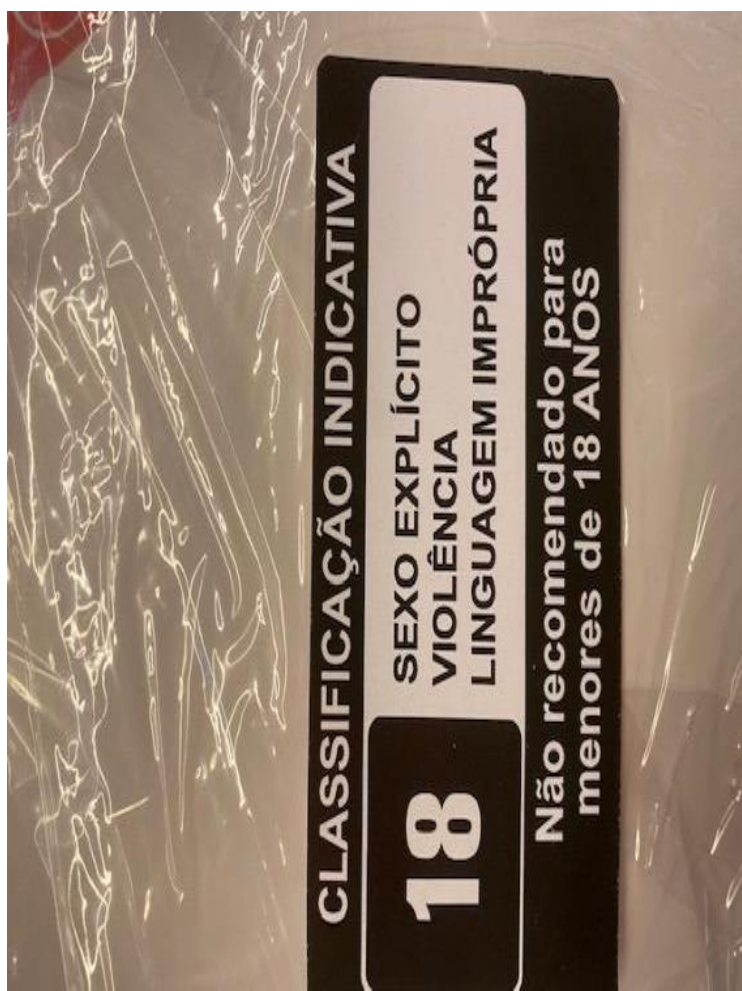

Figura 5 - Tarja preta com a classificação etária

No comunicado asseverava-se que "de acordo com a regulamentação vigente, menores de 18 anos poderão visitar a exposição desde que acompanhados dos pais ou responsáveis". Emitiu-se ainda um comunicado "indicativo" da temperatura vigente no universo das artes naquele contexto: "O único dado absoluto, do qual não podemos abrir mão, é o respeito ao outro, à diferença e à liberdade artística. Portanto, é preciso reafirmar a necessidade e o espaço para o diálogo e que se criem condições para que todos nós - cada um com suas crenças, práticas, orientações políticas e sexualidades - possa conviver de forma harmoniosa".

A medida era, sem dúvida, inédita e fazia ressoar o cancelamento da mostra Queermuseu, em Porto Alegre, e os ataques à performance La Bête, realizada no MAM de São Paulo. Foi logo tomada por muitos como uma "auto-censura". Outros ainda, propunham que a exposição fosse aberta com uma sala especial reunindo todas as obras censuradas.

A segunda proposta foi logo descartada pela curadoria, uma vez que implicava reforçar o argumento daqueles que se opunham à abertura e que pretenderiam ver nessa sala especial uma sorte de arte degenerada, numa alusão à mostra aberta na época da Alemanha Nazista.

A primeira decisão também incorria em ônus. Afinal, nunca uma mostra havia recebido uma indicação rigorosa como essa, e ainda menos um catálogo. Mas foi a que se impôs a despeito da discordância da curadoria. 
No dia da abertura da exposição, o Museu ferveu. Havia a mesma quantidade de pessoas - muito acima da lotação do prédio - dentro e fora do Masp. Boa parte do público opunha-se ao que considerava ser a "censura de 18 anos". Já outra parte estava lá de maneira solidária, pois temia-se nova invasão do MBL.

Alguns artistas nacionais também mostraram adesão, enquanto outros acusaram o golpe, temendo pela própria integridade. Eram sinais desses tempos nervosos com os alguns participantes da mostra pressionando para que a exposição não fosse aberta livremente.

A mostra do Masp, muito antes do incidente ocorrido no Santander, já selecionara a mesma obra da artista Adriana Varejão para figurar em "Histórias da sexualidade", a qual, caso a exposição em Porto Alegre não tivesse sido fechado, iria direto de uma mostra para a outra mostra. Porém, naquele contexto, tudo soava como provocação.

Mas o fato é que a exposição não fechou e nem tampouco encurtou sua duração; a própria censura para 18 anos acabou por cair depois de algumas semanas. Já a exposição, teve uma visitação muito forte, e sua permanência durante o período estabelecido - com direito a uma semana a mais - pareceu sinalizar o arrefecimento da onda moralista que desaguara no mundo e sobre o Brasil.

Sabemos, porém, que esses prognósticos não se cumpririam e que o Brasil entraria de chofre num momento de muita intolerância, ódios partidos e moralismo retrógrado. Por outro lado, a censura do Masp dividiu as opiniões e tomou caráter simbólico. De alguma maneira o passo atrás indicava uma sinalização de temor e medo diante do ambiente político que ressoava dentro do Museu.

Hoje talvez seja mais fácil apostar na ideia de que "nada aconteceria". Mais difícil, como participante do processo, é ter certeza do desfecho. História e memória são categorias de entendimento do tempo. Não há tempo bom entre elas, pois, como diz Beatriz Sarlo, a história desconfia da memória. Já a memória não acredita numa disciplina que não traz a subjetividade e o direito à vida para o centro de seu objeto. Por isso o passado é sempre muito conflituoso. ${ }^{30}$

De toda maneira, a formação de uma cultura pública é imprescindível para proteger a sociedade e as instituições democráticas. Nesse sentido, com o tempo passado, de um lado é importante comemorar o fato do Museu não ter fechado suas portas, de outro, lamentar maior resistência.

30 Sarlo, Beatriz. Tempo passado: cultura da memória e guinada subjetiva. São Paulo, Companhia das Letras; Belo Horizonte: UFMG, 2007. 
O Masp seguiria com sua programação que incluía a exposição “Histórias afroatlânticas" em 2018, "Histórias das mulheres e histórias feministas" em 2019. Nessas duas mostras, o tema voltava à questão da memória e dos silenciamentos da história. No caso das populações de origem africana, tratava-se de recuperar a potência de uma arte negra que cruzou o atlântico e produziu um diálogo visual que não se prendeu a um território. No caso das mulheres, significou tirar dos acervos nacionais e do estrangeiro, obras apagadas e borradas pela história da arte, particularmente afeita ao colonialismo e ao machismo.

Ambas as mostras manteriam a filosofia do grupo curatorial, atento às "histórias", que implicaram sempre em buscar uma perspectiva formalista casada a uma visão mais ativista, diriam alguns, atenta à urgência, explicariam outros. O certo é que o caso de "Histórias da sexualidade" mostrava como o momento era de crise de valores, de ética, de moral, o que aguçava a responsabilidade do Museu, atento e expressão da sociedade. Artes sempre foram bons sinaleiros; ao invés de consequência são causa; anunciam ao invés de apenas espelhar. No exemplo específico ficava alardeada a voga retrógrada que se formalizaria em novembro de 2018. Arte é, também, urgência e antecipação.

\section{Histórias}

“Em tempos de crise fique próximo de um artista". Esse é o conselho que deu Mario Pedrosa, que nunca distinguiu arte de ativismo. No Chile, em sua proposta para um Museu, que não chegou a existir, o crítico chamava atenção para a importância de se construir um Museu como laboratório de experiências históricas, culturais, étnicas, raciais, de gênero. $\mathrm{Na}$ mesma perspectiva destacava a urgência de um Museu democrático, que convidasse a entrar, sem distinções. Um "Museu da retaguarda", provocava ele, que buscasse dar conta de "tudo que foi ficando pra trás". Um Museu como "convocatória", e que fosse capaz de chamar um público transversal. Um Museu "solidário", mas que abrigasse ruídos, contradições, conflitos e não os abafasse. Um Museu como "agente de mudança" e como lugar de encontro dessas várias experiências. Um Museu que pretendesse provocar, incomodar e não acomodar. ${ }^{31}$

Pedrosa vivia em outro momento de urgência, e não podia saber do destino que estava reservado ao Chile, que em 1973 sofreu um golpe particularmente violento que

\footnotetext{
${ }^{31}$ Vide tese de Luiza Mader. (2020) “A opção museológica de Mário Pedrosa: Solidariedade e Imaginação Social em Museus da América Latina". Programa de Doutorado em História da Arte - Interunidades MACUSP.
} 
retirou Salvador Allende do poder para em seu lugar colocar o General Augusto Pinochet, que abriu um período de ditadura naquele país que durou até 1990.

Vivemos no Brasil ainda outra urgência. Mas vai ficando claro como experimentamos um período de clara erosão democrática. A pergunta que resta é: qual o papel de um Museu localizado bem na Avenida Paulista, coração nervoso da capital do Estado de São Paulo e palco para manifestação das mais diferentes tendências políticas e gêneros?

Mas existe mais outra urgência. A História da arte pode ser considerada como um dos pilares mais poderosos e duradouros do imperialismo e da colonização europeia. Embora se baseie em talento e mérito, foi necessário, para que se estabelecesse um cânone, que fossem elaboradas soluções complexas de continuidade e de conexão entre obras, escolas e artistas, para que essa história virasse não só única como contínua. ${ }^{32}$

Esse universo classificou e separou arte (arte Ocidental) de artesanato (os outros povos, muitas vezes chamados de primitivos); arte universal (a arte europeia) de regional (as demais), o erudita do popular. Nesse meio tempo várias escolas, todas europeias, depois norte-americanas, sempre ocidentais, trataram de determinar quem fazia parte do seleto grupo de artistas celebrados e reconhecidos, e quem estava fora. Formou-se assim um modelo bastante estruturado e rígido em que constam mestres, gênios luminares, próceres - e não por coincidência -, em sua imensa maioria, homens.

O certo é que o grupo que entrou no Masp em 2015 abriu seus trabalhos em regime de urgência. Sabemos que em momentos de crise a história vira um player fundamental, com campos opostos usando desse tipo de narrativa do passado para justificar o presente. Já o conceito de História, no caso do Masp, ganhou um sentido múltiplo e plural, uma vez que passou a abranger tanto a não-ficção como a ficção - as histórias que ouvimos, que contamos e que gostamos de contar - ; os relatos que podem ser coletivos mas também individuais; as narrativas de fundo nacional como aquelas que defendem a diferença e o lugar específico de fala. A perspectiva desenvolvida na Instituição também pretende desestabilizar um olhar por demais eurocentrado e homocêntrico. Para isso foi preciso elaborar todo um programa de exposições, mas também ir alterando o acervo do Museu. O Masp é considerado o mais importante museu de arte do Hemisfério Sul, por conta do seu acervo abrangente. São cerca de 8000 peças, em sua grande maioria de arte ocidental, desde o século IV a.c. até os dias de hoje.

\footnotetext{
32 Carneiro, Amanda e Mesquita, André. "Por um MASP Afro-Atlântico”. In: Pedrosa, Adriano et al. (2018) Histórias Afro-Atlânticas: [vol.2] Antologia. São Paulo, MASP.
} 
Tombado pelo IPHAN, o acervo do Museu vem sendo enriquecido e ampliado por meio de doações de pessoas físicas, artistas e parcerias com empresas e instituições. Apenas em 2015 foram realizadas 11 exposições que implicaram no manuseio, enriquecimento de registros, bem como a ampliação dos dados de 1.036 obras do acervo. Além do mais, a realização de exposições sempre gera a oferta e doação de novas obras, todas elas analisadas pela Direção Artística e pelo Comitê Consultivo de Formação de Acervo. Nesse mesmo ano de 2015, foram16 novos trabalhos dentre fotografias, gravura e pinturas.

Entretanto, os desafios que se colocam diante da programação de um museu como o Masp, ou frente aos projetos educativos e pedagógicos apresentam-se também nessa área de acervos. Como ampliar suas coleções de maneira a que elas espelhem a diversidade existente no Brasil? As histórias ameríndias, africanas, populares, imigrantes, feministas e de gênero? Como descolonizar e, ao mesmo tempo, diversificar o acervo eminentemente europeu do Museu? Como realizar um museu de fato democrático sem reificar posições e hierarquias solidificadas na História da Arte? Se o Masp tem o privilégio de contar com o maior acervo europeu fora da Europa, o desafio há de ser complementá-lo, a partir da entrada sistemática e rigorosa de obras, mas também diversificá-lo. Isso é, realizar políticas de inclusão, também no mundo das artes.

O certo é que os museus brasileiros ganharam novas responsabilidades diante da escalada conservadora na política, da entrada de políticos retrógrados que querem fazer retroagir conquistas arduamente conquistadas. O Masp, por mais que seja o resultado da iniciativa privada, já atingiu um espaço simbólico na imaginação do país. O desafio é abrir espaços de interlocução que coloquem em diálogo a história dessa instituição e suas perspectivas abertas, e para o futuro. O desafio é também dialogar com o momento em que vivemos sem abrir mão da potência da arte. Por fim o desafio é manter um museu vivo, decolonial em transformação. Um edifício aberto, democrático é utopia das boas e que nesses momentos obscuros cumpre realizar.

\section{Bibliografia}

Aguilar, Nelson. (2019) Pietro Maria Bardi: construtor de um Novo Paradigma cultural. Campinas, Ed. Unicamp.

Almeida, Rodrigo de. (2016) À sombra do poder; os bastidores da crise que derrubou Dilma Rousseff. São Paulo, Leya.

Bardi, Lina Bo. (1970) “Explicações sobre o Museu de Arte”. O Estado de São Paulo, 05 de abril.

Botelho, André e Starling, Heloisa Murgel (org.). (2017) República e Democracia; impasses no Brasil 
contemporâneo. Minas Gerais, Editora UFMG.

Edwards, Steve. (1999) “Introduction”. Art and its Histories. New Haven, Connecticut, Yale University.

Lima, Zeuler. (2021) Lina Bo Bardi: O que eu queria era ter história. São Paulo, Companhia das Letras.

Mader, Luiza. (2020) “A opção museológica de Mário Pedrosa: Solidariedade e Imaginação Social em Museus da América Latina". Programa de Doutorado em História da Arte - Interunidades MAC-USP.

Miguel, Luis Felipe e Biroli, Flávia. (org.) (2017) Encruzilhadas da democracia. Porto Alegre, Editora ZOUK.

Nora, Pierre. (1993) “Memória e História. A problemática dos lugares”. Proj. História, São Paulo, v.10, dezembro.

Pedrosa, Adriano e Proença, Luiza (org.). (2015) Concreto e cristal: o acervo do MASP nos cavaletes de Lina Bo Bardi. São Paulo, MASP/ Cobogó

Pedrosa, Adriano et al. (2016) A Mão do Povo Brasileiro. São Paulo, MASP. . (2018) Histórias Afro-Atlânticas: [vol.2] Antologia. São Paulo, MASP.

Pedrosa, Adriano; González, Julieta e Proença, Luiza. (2016) Playgrounds 2016. São Paulo, MASP

Safatle, Cláudia, Borges, João, Oliveira, Ribamar. (2016) Anatomia de um desastre; os bastidores da crise econômica que mergulhou o país na pior recessão de sua história. São Paulo, Portfolio-Penguin.

Sahlins, Marshal. (1990) Ilhas de história. Rio de Janeiro, Zahar ed.

Santos, Wanderley Guilherme dos. (2017) A Democracia impedida; o Brasil no século XXI. Rio de Janeiro, FGV Editora.

Scarpin, Paula. (2015) "As telas suspensas de Lina Bo Bardi. O MASP reabilita os cavaletes de cristal". Revista Piauí, edição 111, dezembro.

Schwarcz, Lilia. (2014) Pérola imperfeita: a história e as histórias de Adriana Varejão. Rio de Janeiro, Cobogó. . (2018) Sobre o autoritarismo brasileiro. São Paulo, Companhia das Letras. 